\title{
Numerical evaluation of seismic response of shallow foundation on loose silt and silty sand
}

\author{
Ali Asgari ${ }^{1, *}$, Aliakbar Golshani $^{1}$ and Mohsen Bagheri ${ }^{2}$ \\ ${ }^{1}$ Department of Civil Engineering, Tarbiat Modares University, Tehran, Iran. \\ ${ }^{2}$ Department of Civil Engineering, Babol University of Technology, Babol, Iran. \\ *Corresponding author.e-mail: ali.asgari@modares.ac.ir ali.asgari111@yahoo.com
}

This study includes the results of a set of numerical simulations carried out for sands containing plastic/non-plastic fines, and silts with relative densities of approximately $30-40 \%$ under different surcharges on the shallow foundation using FLAC 2D. Each model was subjected to three ground motion events, obtained by scaling the amplitude of the El Centro (1940), Kobe (1995) and Kocaeli (1999) earthquakes. Dynamic behaviour of loose deposits underlying shallow foundations is evaluated through fully coupled nonlinear effective stress dynamic analyses. Effects of nonlinear soil structure interaction (SSI) were also considered by using interface elements. This parametric study evaluates the effects of soil type, structure weight, liquefiable soil layer thickness, event parameters (e.g., moment magnitude of earthquake $\left(M_{w}\right)$, peak ground acceleration PGA, PGV/PGA ratio and the duration of strong motion $\left(D_{5-95}\right)$ and their interactions on the seismic responses. Investigation on the effects of these parameters and their complex interactions can be a valuable tool to gain new insights for improved seismic design and construction.

\begin{tabular}{rlrll}
\hline \multicolumn{1}{c}{ Nomenclature } & $D_{H}$ & Lateral displacement \\
& & $c_{s}$ & Shear wave velocity of the soil \\
$\varepsilon_{v d}$ & Strain that occurred over the previous & $f$ & Frequency of input motion \\
& cycles - the volumetric & $r_{u}$ & Excess pore water pressure ratio \\
$E_{c}$ & Young's modulus of concrete & $\mathrm{PGA}$ & Peak ground acceleration \\
$\nu$ & Poisson's ratio & $\Delta u$ & Excess pore water pressure \\
$n$ & Porosity & $\sigma_{0}^{\prime}$ & Initial vertical effective stress \\
$\phi$ & Friction angle & $c_{2}, c_{2}, c_{3}$ & Coefficients in predictive equations \\
$C$ & Cohesion & $T_{p}$ & Predominant period \\
$k_{n}$ & Normal stiffness & $k$ & Soil permeability coefficient \\
$k_{s}$ & Shear stiffness & $D_{r}$ & Relative density \\
$\Delta Z_{\text {min }}$ & Smallest dimension of an adjoining zone & $S$ & Vertical displacement \\
& in the normal direction & $\psi$ & Dilation angle \\
$\Delta l$ & Maximum dimension zone & $G$ & Shear modulus \\
$\rho$ & Mass density & $K$ & Bulk modulus \\
$H_{L}$ & Thickness of liquefiable soil layer & $D$ & Depth \\
$\Delta \varepsilon_{v d}$ & Increment of volume decrease & $B_{f}$ & Foundation width \\
$\gamma$ & Cyclic shear-strain amplitude & $d_{f}$ & Foundation depth
\end{tabular}

Keywords. Liquefaction; soil type; thickness of liquefiable soil; earthquake; deformation. 


\section{Introduction}

The prediction of liquefaction and resulting displacements is a major concern for structures located in the regions of moderate to high seismicity (Byrne et al. 2004). This is particularly so for superstructures where large displacements and other types of geotechnical hazard could lead to excessive damage. It is noteworthy that the additional safety in the design of superstructure is not of any help in the event of liquefaction of foundation soil during an earthquake (Mittal et al. 2004). During the past three decades, a large volume of literature has been published on geotechnical earthquake engineering, particularly soil liquefaction and the destructive power of liquefaction (Kramer 1996; Finn 2000; Youd 2003).

Most natural and artificial (e.g., hydraulic fills) sand deposits contain some fines and most of the soils experienced liquefaction during previous earthquakes have contained some percentages of fines (Yasuda et al. 1994; Wijewickreme et al. 2005; Bray and Sancio 2006). Case histories, laboratory and field evidence indicate that soil types prone to liquefaction and developing large shear deformations are loose sand, silty sand/sandy silt containing mostly non-plastic silt, and gravel (Erten and Maher 1995; Amini and Qi 2000; Salgado et al. 2000; Polito and Martin II 2001; Yamamuro and Covert 2001; Thevanayagam and Martin 2002). Some concluded that increasing fines content decrease the liquefaction potential, whereas others observed the opposite. Still, despite the amount of related research, results seem somewhat contradictory (Bouckovalas et al. 2003). In addition, extensive research has been devoted in the past years to investigate the mentioned concerns regarding the effect of structure (e.g., building, rock-fill embankments and earth dams) on liquefiable soils.

Rollins and Seed (1990) gave a comprehensive review of the experimental research and case histories from the literature concerning the potential for liquefaction below a building as well as soil-structure interaction effects on the potential for liquefaction. They showed that presence of an initial static shear stress induced by a building increases the liquefaction resistance of denser sands and decreases the liquefaction resistance of looser sands. Dashti et al. (2009a, b) gave a qualitative evaluation of the effects of some key parameters (shaking intensity, the liquefiable soil's relative density and thickness, and the building's weight and width) on liquefaction-induced settlements of buildings.

Although recent advances in physical model experiments (Vucetic and Dobry 1991; Pillai and Byrne 1994; Baziar and Dobry 1995; Liu and Dobry 1997; Høeg et al. 2000; Boulanger 2003;
Carraro et al. 2003; Huang et al. 2004; Boulanger and Idriss 2006; Polito et al. 2008; Hazirbaba and Rathje 2009), field case histories (Adalier et al. 1998; Yoshida et al. 2001; Bray et al. 2004) and computational modelling of liquefaction-induced ground deformation (Di and Sato 2004; Yang et al. 2004; Wang et al. 2006; Rayhani and El Naggar 2008; Shahir and Pak 2010; Asgari et al. 2013) are quite promising, challenges remain on this critical problem.

In this paper, for the accuracy in the assessment of the likelihood of liquefaction at a site four factors affecting the safety and cost of the design are evaluated: structure weight, soil type, liquefiable soil layer thickness $\left(H_{L}\right)$, and the characteristics of the earthquake. Results of the analyses are interpreted in order to improve understanding of the liquefiable soils seismic response.

\section{Numerical simulations}

\subsection{Model geometry and soil properties}

A series of numerical analyses are carried out to investigate various factors affecting the seismic performance of buildings with shallow foundations, including structure weight, soil type, liquefiable soil layer thickness $\left(H_{L}\right)$, and ground motion characteristics. The Mohr-Coulomb model was used to simulate the nonlinear soil behaviour. The model is based on plane strain conditions and is formulated in terms of effective stresses. The shallow foundation was modelled as a linearly elastic material, by using beam element with bending stiffness of $E_{c} I=1.53 \times 10^{8} \mathrm{kN} \cdot \mathrm{m}^{2}$ (American Concrete Institute (ACI) 2008). Table 1 presents the soil and shallow foundation parameters used in the model. According to figure 1, three structures with different numbers of stories were considered in the parametric analyses in order to assess the effect of structure weight on the seismic behaviour of the liquefiable soils.

Structures A, B, C represent a 5, 8 and 12storey building with a contact pressure of 50, 80 and $120 \mathrm{kPa}$, respectively.

The numerical simulation includes a liquefiable soil layer with a prototype thickness $\left(H_{L}\right)$ of $20 \mathrm{~m}$ underlying a layer of gravel soil with thickness of $10 \mathrm{~m}$. A series of realistic earthquake motions (table 2) were applied to the base of the model (figure 1) consecutively in each analysis. Figure 2 shows acceleration-time histories and fast Fourier transform of the input events for three different ground motions. The input motions included a sequence of scaled versions of components of the El Centro (1940), the Kobe Port Island (1995) and 
Table 1. Soil and foundation data for deterministic analysis.

\begin{tabular}{llll}
\hline Soil property & Loose silty sand & Loose silt & Gravel \\
\hline Moist unit weight, $\gamma(\mathrm{kg} / \mathrm{m})$ & 1650 & 1500 & 2100 \\
Elastic modulus, $E(\mathrm{MPa})$ & 15 & 10 & 140 \\
Relative density, $D_{r}(\%)$ & 30 & 30 & - \\
Internal friction angle, $\phi($ degree $)$ & 30 & 25 & 40 \\
Dilation angle, $\psi($ degree $)$ & 0 & 0 & 10 \\
Permeability coefficient, $k(\mathrm{~m} / \mathrm{s})$ & $1 \times 10^{-6}$ & $1 \times 10^{-8}$ & $1 \times 10^{-2}$ \\
Drained cohesion, $C(\mathrm{kPa})$ & 0 & 3 & 1 \\
Porosity, $n$ & 0.412 & 0.474 & 0.25 \\
Bulk modulus, $K(\mathrm{MPa})$ & 12.5 & 16.6 & 94 \\
Shear modulus, $G(\mathrm{MPa})$ & 5.625 & 3.57 & - \\
Poisson's ratio, $\nu$ & 0.3 & 0.4 & $2 \times 10^{4}$ \\
Normal stiffness, $k_{n}(\mathrm{kPa} / \mathrm{m})$ & $2.1 \times 10^{4}$ & $2 \times 10^{4}$ & \\
Shear stiffness, $k_{s}(\mathrm{kPa} / \mathrm{m})$ & $2.1 \times 10^{4}$ & 8 & \\
$N_{1}(60)$ (blows) & 10 & & \\
Foundation data & & 15 & \\
\hline Foundation width, $B_{f}(\mathrm{~m})$ & & $2.3 \times 10^{11}$ & \\
Young's modulus concrete, $E_{c}(\mathrm{kPa})$ & & & \\
\hline
\end{tabular}

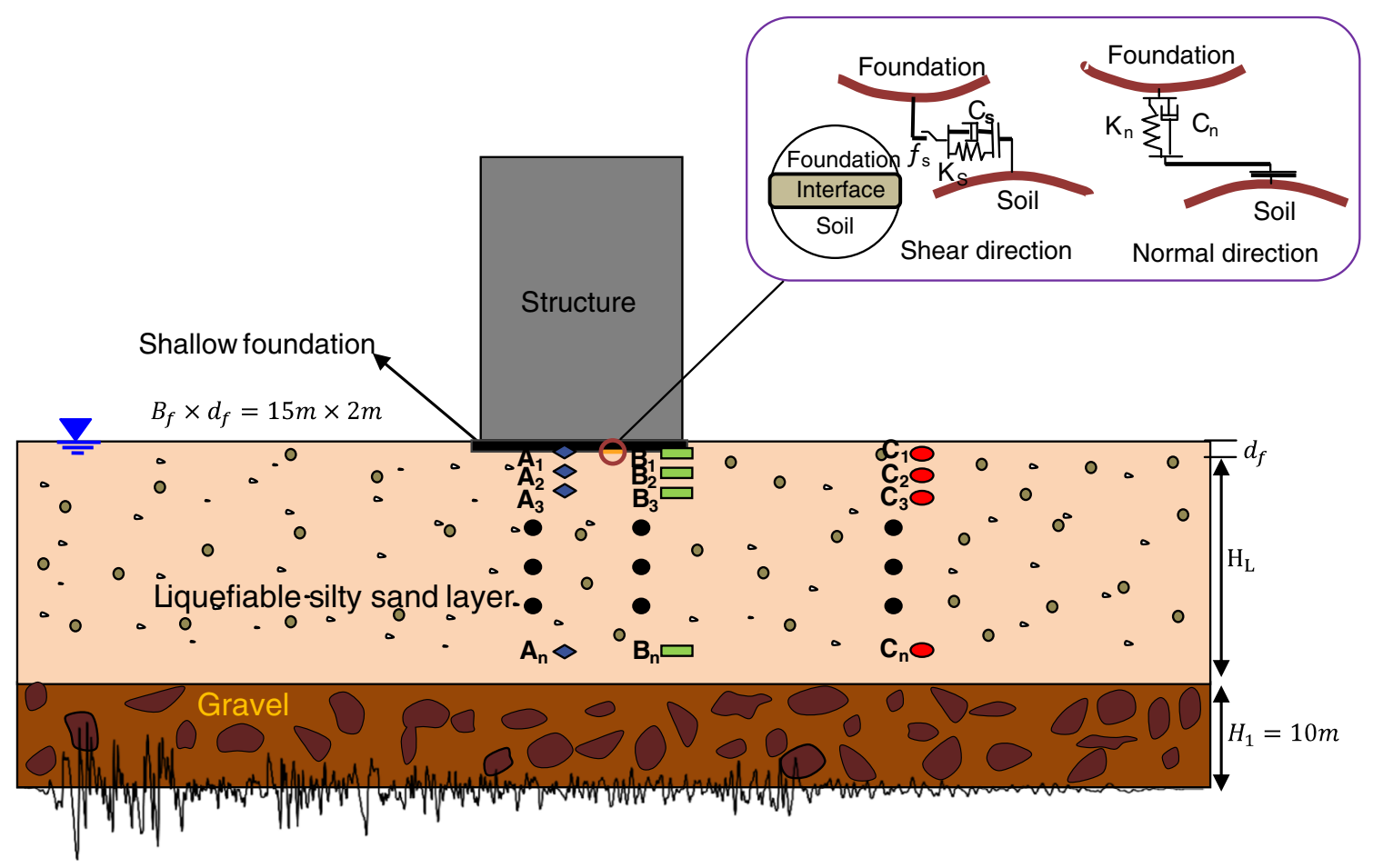

Figure 1. Schematic illustration of structure constructed on shallow foundations subjected to earthquake and details of the constitutive law of normal and shear contact forces at the interface between foundation and liquefiable soil.

the Kocaeli (1999) Turkey earthquakes. The foregoing earthquake time histories were chosen for two main reasons:

(a) They have different acceleration time history waveforms (e.g., the El Centro excitation has 12.5 significant cycle of excitation, while the
Kobe and Kocaeli excitations have almost 10.2 and 4.6 significant cycles, respectively).

(b) They have been related to large ground failures and extensive liquefaction phenomena.

A soil profile with a width of $480 \mathrm{~m}$ was used in the following sections to decrease any boundary 
Table 2. Earthquake data for the parametric analysis.

\begin{tabular}{|c|c|c|c|}
\hline $\begin{array}{l}\text { Earthquake motion } \\
\text { parameters/component }\end{array}$ & $\begin{array}{c}\text { El Centro (USA) } \\
\text { N-S }(180)\end{array}$ & $\begin{array}{l}\text { Kobe (Japan) } \\
\text { E-W(090) }\end{array}$ & $\begin{array}{c}\text { Kocaeli (Turkey) } \\
(330)\end{array}$ \\
\hline Date of occurrence & $05 / 19 / 1940$ & 01/16/1995 & 08/17/1999 \\
\hline Recording station & 117 El Centro & $\begin{array}{l}\text { Kakogaw, } 090 \\
\text { (CUE) }\end{array}$ & $\begin{array}{l}\text { Yarimca, } 330 \\
\text { (KOERI) }\end{array}$ \\
\hline Maximum horizontal acceleration (MHA) (g) & $0.313 \mathrm{~g}$ & $0.345 \mathrm{~g}$ & $0.349 \mathrm{~g}$ \\
\hline Predominant period (sec) & 0.46 & 0.16 & 1.4 \\
\hline Bracketed duration (sec) & 35.9 & 34.42 & 18.04 \\
\hline Significant duration $\left(D_{5-95}\right)(\mathrm{sec})$ & 24.1 & 12.86 & 10.69 \\
\hline Time of MHA $\left(t_{p}(\mathrm{sec})\right)$ & 2.15 & 6.98 & 4.8 \\
\hline PGV/PGA (sec) & 0.097 & 0.082 & 0.181 \\
\hline Arias intensity in $\mathrm{PGA}=0.55 \mathrm{~g}$ & 5.265 & 4.296 & 3.113 \\
\hline Energy flux in PGA $=0.55 \mathrm{~g}\left(\mathrm{~J} \cdot \mathrm{m}^{-2} \cdot \mathrm{sec}^{-1}\right)$ & 4924 & 4139 & 25764 \\
\hline Moment magnitude of earthquake $\left(M_{w}\right)$ & 7.1 & 6.9 & 7.4 \\
\hline Number of significant excitation cycles $\left(N_{c}\right)$ & 12.5 & 10.2 & 4.6 \\
\hline
\end{tabular}
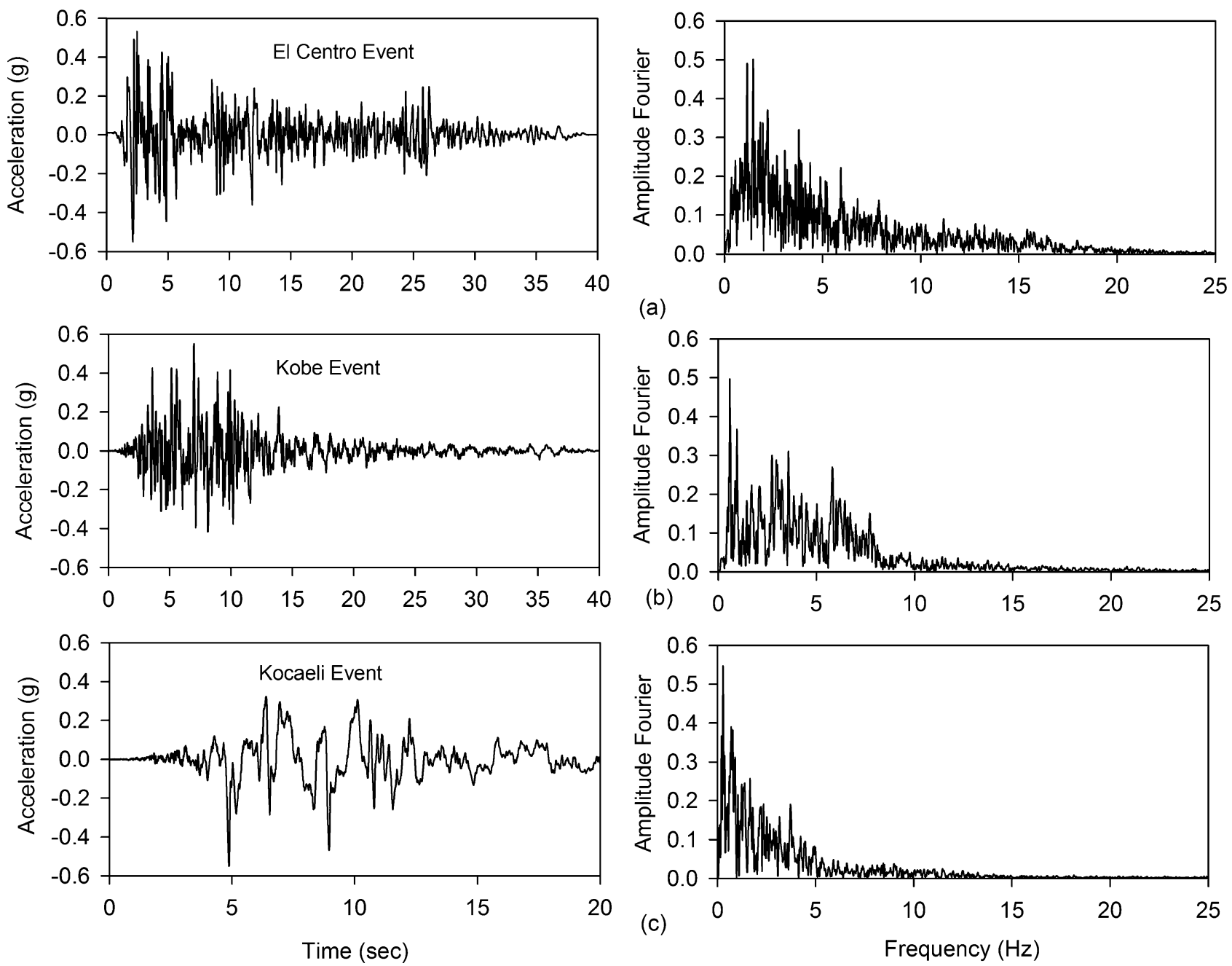

Figure 2. Horizontal acceleration history for (a) El Centro, (b) Kobe and (c) Kocaeli seismic zones and their fast Fourier transforms of the input signal, respectively.

effect (figure 1). The elements with 4 nodes and dimension of $1 \mathrm{~m}$ were chosen for this purpose. Interaction of soil foundation proprieties is also defined by an interface element which is a twodimension element with plane strains only.
The mesh size and the maximum unbalanced force at the grid points (i.e., error tolerance) were selected on the basis of a series of parametric analyses to concurrently optimize accuracy and computation speed. 


\subsection{Soil-structure interface}

Soil-structure interaction effects on liquefaction potential are also examined employing interface elements. The interfaces between the foundation and soil were modelled as linear spring-slider systems, with interface shear strength defined by the Mohr-Coulomb failure criterion. The relative interface movement is controlled by interface stiffness values in the normal $k_{n}$ and the tangential $k_{s}$ directions. Based on the recommended rule-of-thumb estimates for maximum interface stiffness values given by Itasca Consulting Group (Itasca 2002), $k_{n}$ and $k_{s}$ were set to 10 times of the equivalent stiffness of the neighbouring zone. The apparent stiffness (expressed in stress per distance units) of a zone in the normal and tangential directions is:

$$
k_{n(\max )}=k_{s(\max )}=10 \times \max \left[\frac{K+4 G / 3}{(\Delta Z)_{\min }}\right]
$$

where $K$ and $G$ are the bulk and shear modules of soil zone, respectively (table 1 ), and $\Delta Z_{\text {min }}$ is the smallest dimension of an adjoining zone in the normal direction.

Table 1 summarizes the interface stiffness properties used in the foundation simulations after adjustment from values calculated by using equation (1).

\subsection{Analysis approach}

\subsubsection{Static analysis}

The degree of strain weakening (strain softening), and seismic response depends on the initial state of the material and its properties (Høeg et al. 2000). The initial geostatic stress for steady state in a free field is one of the primary values related to grid zones which forces the model to reach equilibrium by performing mechanical calculations. In the static analysis, the soil-structure system was under gravity loading only; the base boundary was fixed in all directions and the side boundaries were fixed in $\mathrm{x}$ direction. It should be noted that during the static analysis, flow calculation option in the program should be turned off. Furthermore, in order for pore water pressure not to interact with mechanical volume changes, the water bulk modulus was assumed zero.

\subsubsection{Dynamic analysis}

After performing static analysis under the static effective stress conditions, the following steps were adopted to carry out dynamic analysis:

Step 1. In order to use horizontal component of the acceleration record as input event, it is essential to accomplish baseline correction on above-mentioned histories first. As a result, after integrating the acceleration histories twice, the obtained displacement does not reach zero value at the end of the motion. One approach for correcting this error is to add a low frequency wave to earthquake loading so that displacement reaches zero in the end.

Step 2. Another issue in dynamic loading which is of considerable importance is the wave propagation in the model. Generally, in performing dynamic analyses the presence of error in the form of wave propagation is likely to happen. The finite difference grid dimensions were selected by taking into account the maximum frequency $(f)$ of the shear wave that the model could logically respond to during earthquake loading. Consequently, this prevents the incorrect propagation of the waves. The frequency is determined by the following equation (Kuhlemeyer and Lysmer 1973):

$$
f=\frac{c_{s}}{10 \Delta l}
$$

where $c_{s}$ is the shear wave velocity of the soil and $\Delta l$ is the largest grid zone size in the model. Referring to equation (2), a uniform zone size of $1 \mathrm{~m} \times$ $1 \mathrm{~m}$ was selected. Since the lowest shear wave velocity in the model belongs to the soil deposits, the highest admissible frequency for a propagating shear wave is $5 \mathrm{~Hz}$. Therefore, the input earthquake record shall be filtered by a low pass filter to remove frequency components higher than $5 \mathrm{~Hz}$. A frequency of $4 \mathrm{~Hz}$ was ultimately selected as the low pass filter for the reduction in shear wave velocity which may occur due to plastic flow during seismic loading.

Step 3. Application of dynamic boundary conditions: In order to enforce free-field conditions in the numerical boundaries of the discrete half space foundations, free-field boundary conditions in the code were adopted for lateral boundaries. As for the horizontal boundary, the simulation of outward propagating waves in the foundation was achieved by employing the absorbing boundary conditions available in the finite difference code. It was shown that absorbing boundaries are effective in absorbing outward propagating waves for simulating half space conditions (White et al. 1977). The viscous boundaries developed by Lysmer and Kuhlmeyer (1969) were adopted in the finite difference code, and employed in the analyses herein. Horizontal components of the acceleration records from the El Centro, Kobe Port Island and Kocaeli earthquakes were applied to the base of the model. Since quiet boundaries were already attributed to the horizontal boundaries, the acceleration history of the input 
motion was converted to shear stress wave. The process of converting an acceleration time history into a shear wave time history has been described in FLAC manual (Itasca 2002).

Step 4. Rayleigh damping, which consists of two viscous elements, is conventionally used in the numerical analyses herein. The two elements of Rayleigh damping are both frequency dependent (Lysmer and Kuhlmeyer 1969). By choosing a mid frequency at which the combined effects of the two elements cancel out, it is possible to have a damping that is nearly independent of frequency over a fairly wide range of frequencies on either side of the mid-frequency (White et al. 1977). The mid-frequency is usually chosen in the range between the natural frequency of the model and the predominant frequency of the input motion. Rayleigh damping was assigned to each element of the model in the mid-frequency. In analyses that use one of the plasticity constitutive models (e.g., Mohr-Coulomb), a considerable amount of energy dissipation can occur during plastic flow (viscous damping). Thus, for many dynamic analyses that involve large-strain, only a minimal percentage of damping (e.g., 5\%) may be required (Itasca 2002). Therefore, the damping ratio was assumed to be $5 \%$ in the analyses. Dynamic analyses were performed and the results were extracted for interpretation and further assessment.

\subsection{Equilibrium equations and constitutive model}

During dynamic analyses, pore fluid simply responds to changes in pore volume caused by mechanical dynamic loading. The average pore water pressure does not vary significantly during the analysis (Itasca 2002). It is known, however, that pore water pressure may build up considerably during cyclic shear loading. It is important to incorporate this physical process in the coupled nonlinear dynamic analysis. Martin et al. (1975) proposed the following empirical equation which relates the increment of volume decrease, $\Delta \varepsilon_{v d}, \gamma$ to the cyclic shear-strain amplitude:

$$
\Delta \varepsilon_{v d}=c_{1}\left(\gamma-c_{2} \varepsilon_{v d}\right)+\frac{c_{3} \varepsilon_{v d}^{2}}{\gamma-c_{4} \varepsilon_{v d}}
$$

A modified two-parameter effective stress model (equation 3) was proposed by Byrne later (1991):

$$
\frac{\Delta \varepsilon_{v d}}{\gamma}=c_{1} \exp \left(-c_{2} \frac{\varepsilon_{v d}}{\gamma}\right)
$$

where $c_{1}$ and $c_{2}$ are constants with different interpretations from equation (3), $c_{1}$ and $c_{2}$ can be derived from relative density, $D_{r}$ as follows:

$$
c_{1}=7600\left(D_{r}\right)^{-2.5}
$$

$$
c_{2}=\frac{0.4}{c_{1}}
$$

Further, Byrne (1991) presented an empirical relation between $D_{r}$ and normalized standard penetration test $\left(N_{1(60)}\right)$, as shown below:

$$
\begin{gathered}
D_{r}=15\left(N_{1(60)}\right)^{0.5} \\
c_{1}=8.7\left(N_{1(60)}\right)^{-1.25}
\end{gathered}
$$

The above-mentioned formulation is available in FLAC as a built-in model and was adopted in this study along with a bilinear, elastic-perfectly plastic stress-strain relationship and Rayleigh damping. Therefore during dynamic analysis, as effective stresses decrease with pore water pressure increment, the soil begins to yield and increments of permanent deformation are accumulated.

The approach described above has been verified and calibrated in the literature through analysis of well-documented centrifuge model tests (Dashti et al. 2009a) and was adopted in this study for the dynamic analysis of the model. The validation lends credence to the use of numerical method in obtaining surcharge effect exerted from the structure on shallow foundation in liquefiable soil.

\section{Effects of some key parameters on numerical modelling of seismic response of shallow foundation on loose soil}

This section describes the effects of structure weight, soil type, liquefiable soil layer thickness $\left(H_{L}\right)$ and the characteristics of the earthquake motion on seismic response of liquefiable deposits. The numerical simulations were conducted for a representative set of weak to strong events.

\subsection{Effect of structure weight on the seismic responses}

Many structures were damaged by ground failure due to liquefaction/cyclic softening of shallow silt and silty sand deposits. Figure 3 shows net excess pore water pressure at the edge of structure $\mathrm{C}$ compared to the free-field in loose silt and loose silty sand during the Kocaeli event $(\mathrm{PGA}=0.15$, $0.35 \mathrm{~g}$ ). Results of the parametric analyses show that both smaller and larger excess pore water pressure can be expected to develop under structure compared to the free-field. It can be noted that both types of soils under heavier structures show more resistance to pore water pressure generation and liquefaction, when subjected to weak ground 

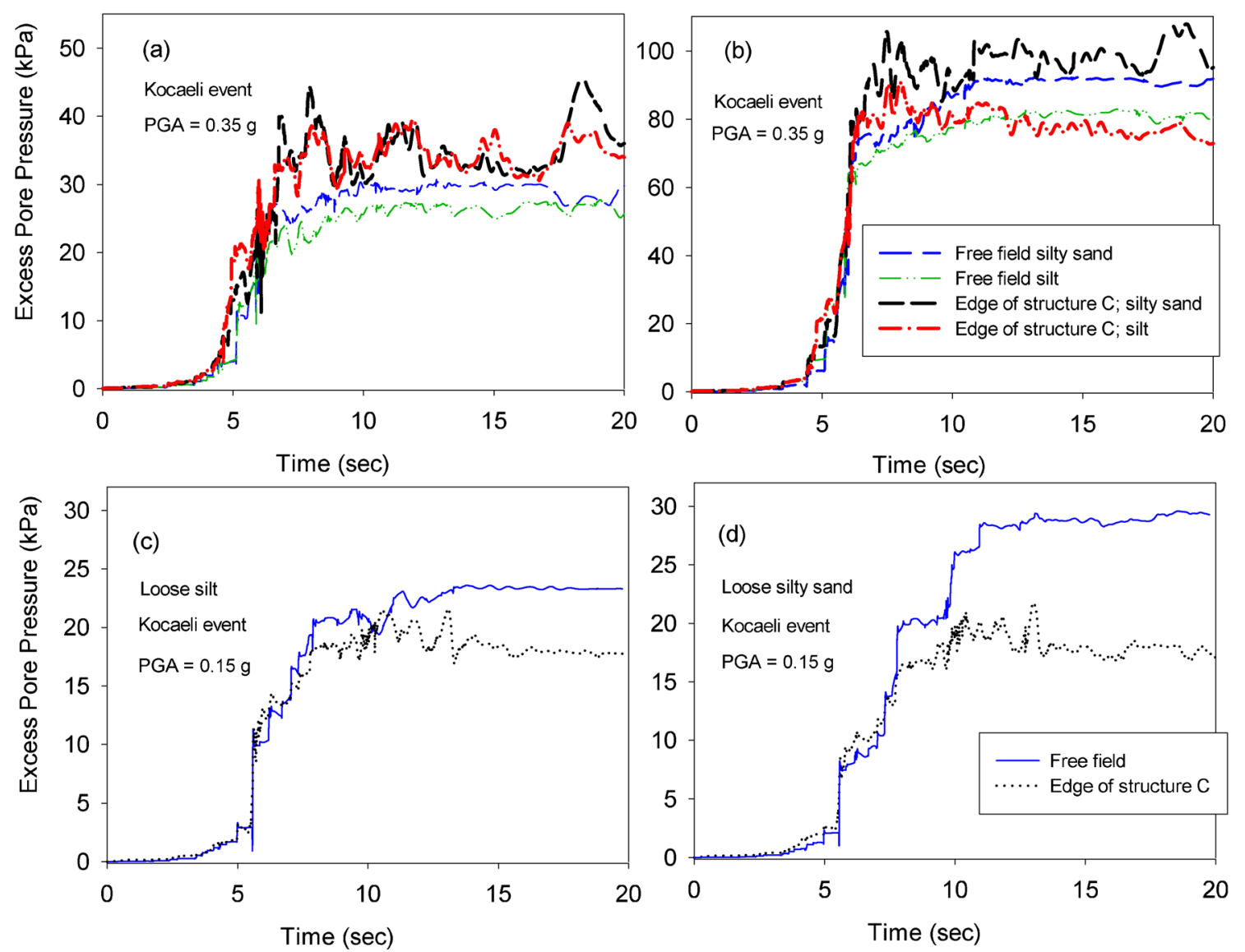

Figure 3. Excess pore water pressure records at depth; (a, c, d) $4 \mathrm{~m}$ and (b) $10 \mathrm{~m}$ of the liquefiable layer in the free-field and the edge of foundation in silty sand and silt during the Kocaeli event.

motions and its effects would be expected to manifest at the surface. However, if the earthquake is strong enough to produce required energy to overcome this resistance, larger excess pore water pressures would be generated under the structure compared to the free-field. This can affect most of the mechanisms of liquefaction-induced displacement during and after earthquake even if it does not fully liquefy. It should be mentioned that similar results were observed for all events (not shown here). Excess pore water pressure ratio $\left(r_{u}\right)$, obtained at the end of earthquake loading for different structures and soils are also presented in figure 4.

In contrast to the observed behaviour in the free-field, the minimum excess pore water pressure ratio under the foundation occurs at shallow depths and the maximum excess pore water pressure ratio occur at intermediate depth. However, this ratio for under structures is always smaller than for freefield (see figure 4). These results are consistent with the findings from the published literature (Dashti et al. 2009a). Two probable explanations for this fact are: (1) the increase in effective stress inducedstructure and/or the static shear strength, or
(2) the redistribution of pore fluid away from this area out towards free-field that prevents the excess pore water pressures from increasing to $100 \%$ of initial vertical effective stress. It can be deduced from figures 3 and 4 that the existence of structure on loose soil layer can decrease liquefaction, especially during weak earthquake. However, these soils underwent notable non-uniform vertical deformation and deform horizontally underneath the structure foundation for each three ground motion event, especially during the strong shaking (figures 5 and 6), despite its low $r_{u}$.

The presence of the structure creates an increment in the surcharge pressure in the soil below the foundation and thus has a significant effect on deformation during strong earthquakes, which decreases with depth. The most vertical and lateral displacement of the soil stratum in shallow depth below foundation is mainly dependent on the earthquake-induced shear stresses and structureinduced static and dynamic shear stresses. For the case with the minimum excess pore water pressure ratio (structure $\mathrm{C}$ ), horizontal and vertical displacements are also presented in figures 5 and 6 . Soil below structure $\mathrm{C}$ was potentially liquefiable, 

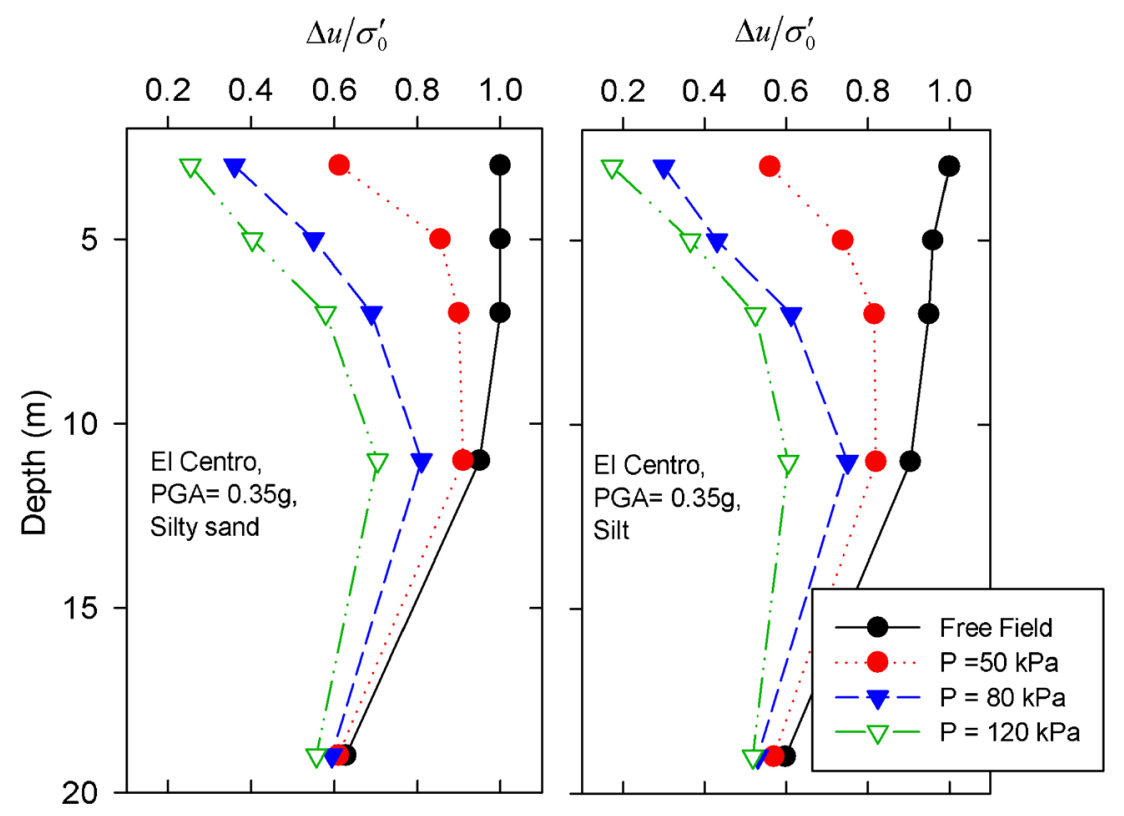

Figure 4. Variation of $r_{u}$ versus depth in silty sand and silt deposits in critical points (along the edge of foundation) subjected to the El Centro event.

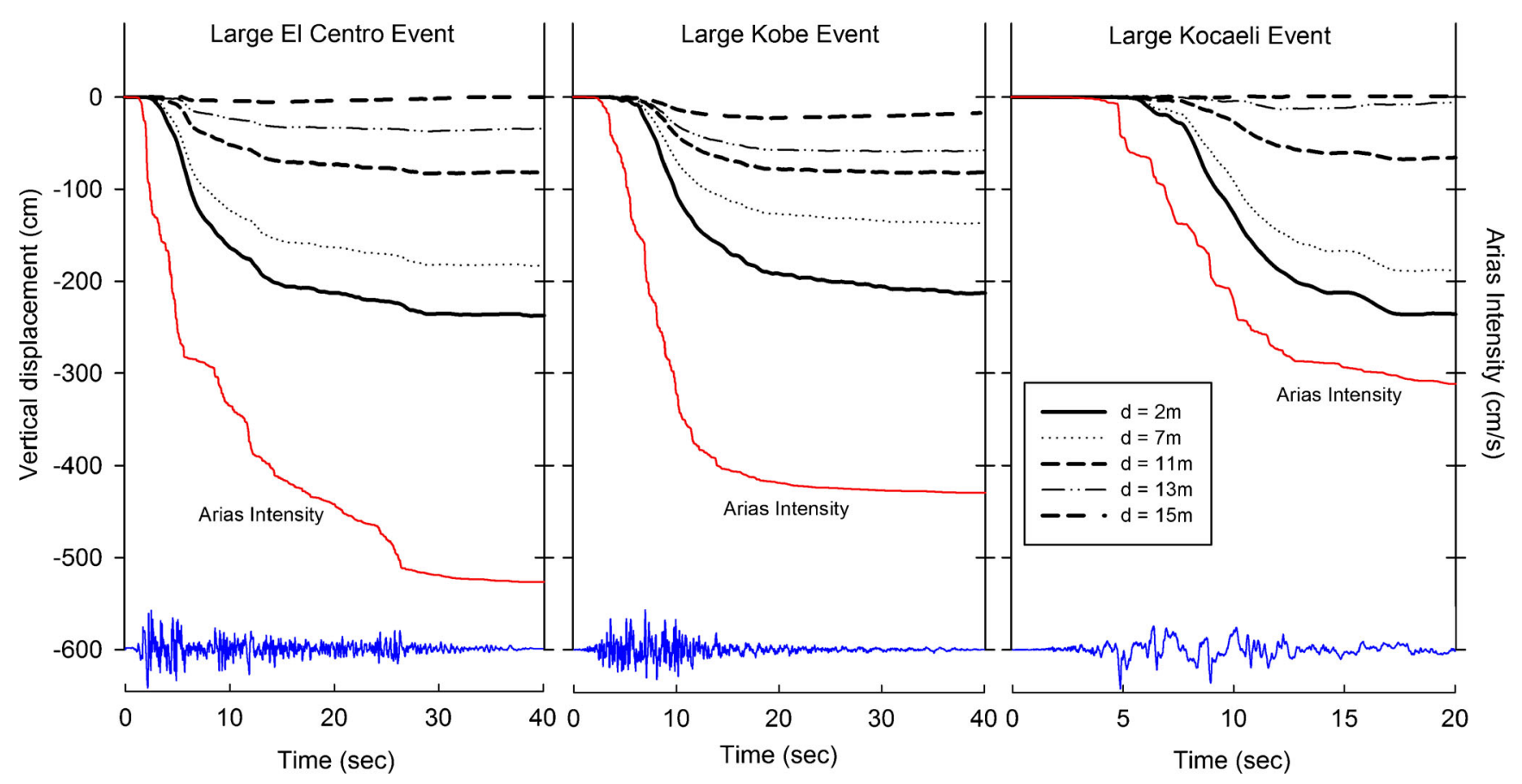

Figure 5. Simulation data for the history of the settlement at various depths along the edge of structure $\mathrm{C}$ during the large: (a) El Centro, (b) Kobe and (c) Kocaeli events PGA $=0.55 \mathrm{~g}$.

and exhibited significantly higher cyclic strength than structure A, B and free-field (strong earthquake). However, it is largely detrimental to structure performance in both types of soils because of large deformation occurrence near the edges of the foundation, as shown in figures 5 and 6 .

The combined effect of vertical and horizontal deformation under structure compels them to tilt excessively which may lead to severe damage to an adjacent lighter/heavier structure. Investigations show that prediction of seismic liquefaction potential is highly dependent to the deformations (Asgari et al. 2013). This suggests that the seismic remedial designs should be based on displacement criteria rather than the factor of safety against liquefaction. 

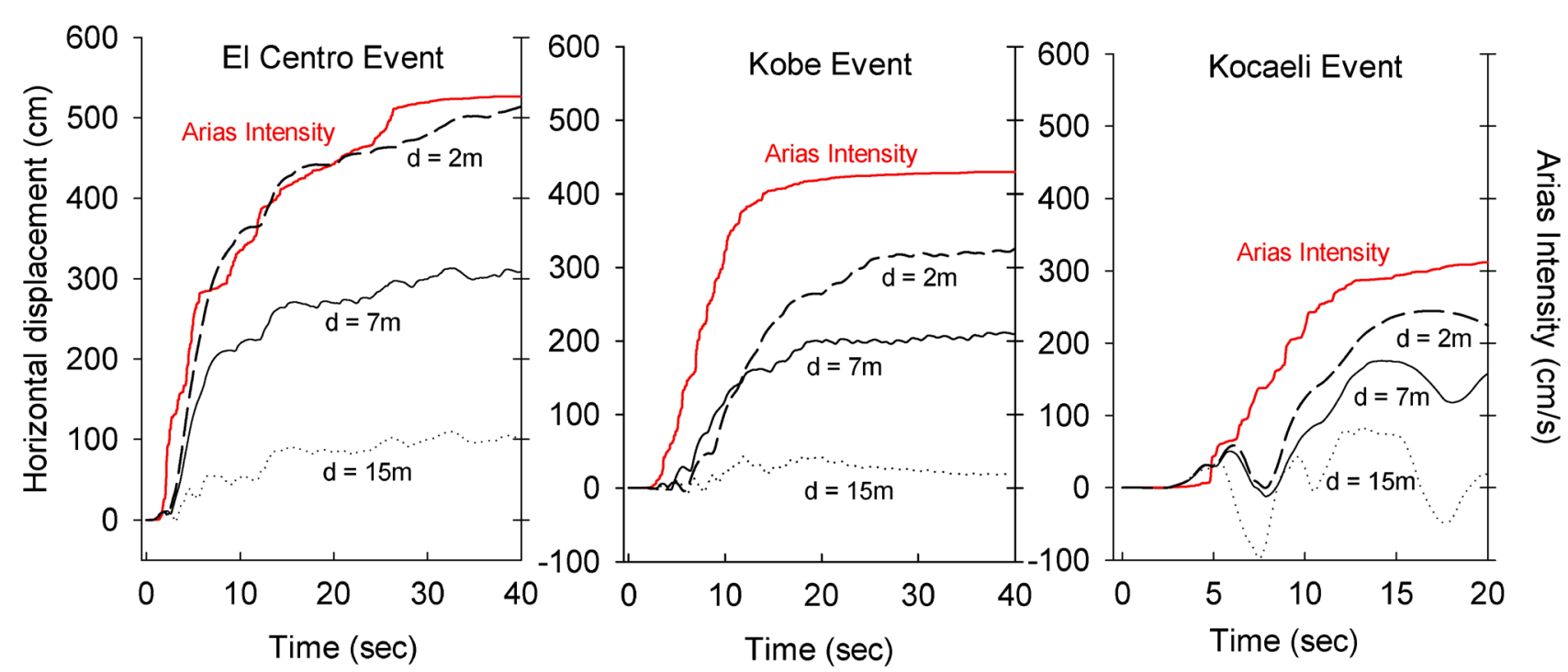

Figure 6. Time history of the lateral displacement profiles of loose silty sand at the edge of structure $\mathrm{C}$ during the large: (a) El Centro, (b) Kobe and (c) Kocaeli events PGA $=0.55$ g.

Table 3. Silty sand and silt stratum: maximum vertical displacement (cm) under structure C for different peak base acceleration PGA, input motions.

\begin{tabular}{|c|c|c|c|c|c|c|c|c|c|c|}
\hline \multirow[b]{2}{*}{ Soil } & \multirow{2}{*}{$\begin{array}{l}\text { Position/ } \\
\text { PGA }\end{array}$} & \multicolumn{3}{|c|}{ El Centro (1940) } & \multicolumn{3}{|c|}{ Kobe (1995) } & \multicolumn{3}{|c|}{ Kocaeli (1999) } \\
\hline & & $0.15 \mathrm{~g}$ & $0.35 \mathrm{~g}$ & $0.55 \mathrm{~g}$ & $0.15 \mathrm{~g}$ & $0.35 \mathrm{~g}$ & $0.55 \mathrm{~g}$ & $0.15 \mathrm{~g}$ & $0.35 \mathrm{~g}$ & $\overline{0.55 \mathrm{~g}}$ \\
\hline \multirow[t]{2}{*}{ Silty sand } & Center & 7.9 & 87 & 116 & 6.5 & 64 & 98 & 10.6 & 113 & 130 \\
\hline & Edge & 36.1 & 132 & 237 & 28.5 & 113 & 213 & 43.3 & 195 & 238 \\
\hline \multirow[t]{2}{*}{ Silt } & Center & 3.3 & 64 & 88 & 2.8 & 40 & 65 & 5.6 & 80 & 95 \\
\hline & Edge & 20.8 & 105 & 195 & 17.6 & 78 & 144 & 27.5 & 178 & 190 \\
\hline
\end{tabular}

\subsection{Influence of soil type on the seismic responses}

This section focuses on the effect of soil type on both deformations and excess pore water pressure generation. From the numerical study, a similar behaviour observed in silty sand and silt is that most of the incremental changes of excess pore water pressure occur during the strong motion. When this strong motion is finished, no significant excess pore water pressure would generate and it remained roughly constant at their peak values. However, as expected, the partial drainage and dissipation process in the silty sand, take place faster than in the silt (figure 3). According to figure 3 (a, b), comparison of pore water pressures in 4 and $10 \mathrm{~m}$ depths, it is observed that by increasing the depth, pore water pressure increases, and also it possesses a higher value rather than in free-field (during moderate event). This case leads to a significant hydraulic gradient that forms vertically upward and horizontally away from the shallow foundations after a few seconds of strong shaking during the three events. This upward flow may even lead to generation of seepage induced liquefaction, causing additional large deformations or loss of bearing capacity under the structures (Martin et al. 1975). Regarding the large hydraulic gradients in the silty sand, higher and larger deformations are expected rather than in the silt which tends to rise by increasing the weight of structure. As presented in table 1 , silt has the mechanical properties, e.g., $N_{1(60)}$ and $E$ less than silty sand. Simulation results brought in tables 3 and 4 show that the more deformations occur in silty sand. This is due to the higher permeability coefficient (hydraulic characteristic) and lower cohesion of silty sand compared to that of silt. Furthermore, permeability plays an important role in determining the liquefaction response of a liquefiable deposit, affecting especially the cyclic softening, and the character of the deformation. As shown in tables 3 and 4 , increasing the permeability leads to increase in settlement and lateral displacement. The influence of the fines content (FC) on the predicted $r_{u}$ and deformation as a function of the 
Table 4. Silty sand and silt stratum: maximum horizontal displacement (cm) under structure C for different peak base acceleration PGA, input motions.

\begin{tabular}{|c|c|c|c|c|c|c|c|c|c|c|}
\hline \multirow[b]{2}{*}{ Soil } & \multirow{2}{*}{$\begin{array}{l}\text { Position/ } \\
\text { PGA }\end{array}$} & \multicolumn{3}{|c|}{ El Centro (1940) } & \multicolumn{3}{|c|}{ Kobe (1995) } & \multicolumn{3}{|c|}{ Kocaeli (1999) } \\
\hline & & $0.15 \mathrm{~g}$ & $0.35 \mathrm{~g}$ & $0.55 \mathrm{~g}$ & $0.15 \mathrm{~g}$ & $0.35 \mathrm{~g}$ & $0.55 \mathrm{~g}$ & $0.15 \mathrm{~g}$ & $0.35 \mathrm{~g}$ & $0.55 \mathrm{~g}$ \\
\hline Silty sand & Edge & 49.8 & 370 & 530 & 22.8 & 231 & 325 & 16.8 & 205 & 244 \\
\hline Silt & Edge & 33.7 & 285 & 474 & 18.6 & 170 & 278 & 10.3 & 158 & 216 \\
\hline
\end{tabular}

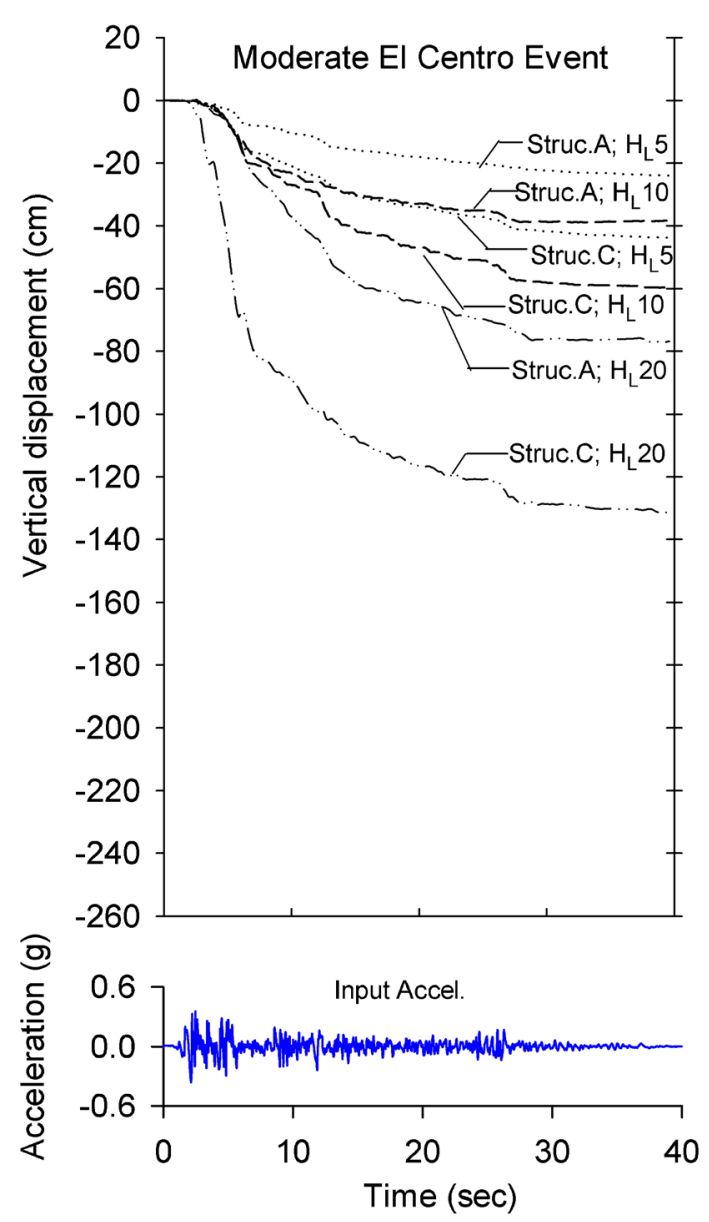

(a)
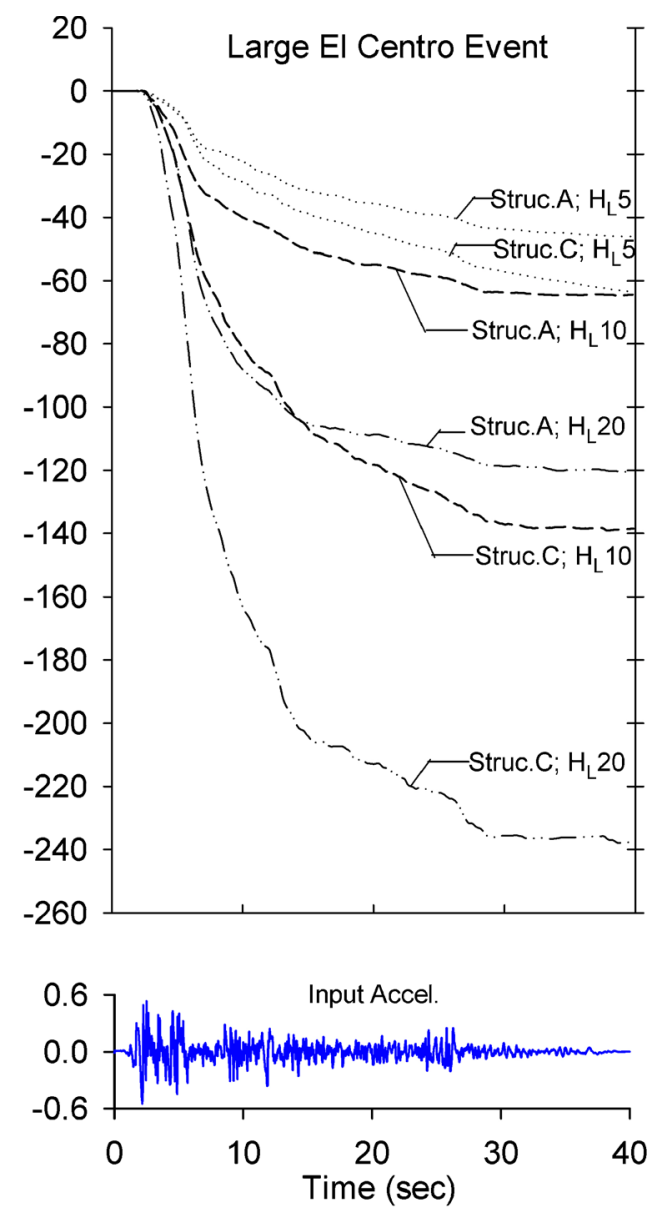

(b)

Figure 7. Vertical displacement-time histories along the edge of the foundation in silty sand during: (a) the moderate $(\mathrm{PGA}=0.35 \mathrm{~g})$ and $(\mathbf{b})$ the large $(\mathrm{PGA}=0.55 \mathrm{~g})$ El Centro events.

properties of the structure (e.g., weight), liquefiable soil (e.g., soil permeability), and the ground motion (e.g., PGA, duration and frequency content) are shown in figures 3,4 and tables 3,4 . As observed from these figures, FC has slightly significant influence on the predicted $r_{u}$ for weak to strong events. However, for weak events as the FC increases, the $r_{u}$ is predicted to slightly decrease. It is noteworthy that beneficial effects of the plastic fines (high-plasticity fine-grained soil deposits) decrease for stronger earthquake and heavier structure. By comparing the deformations of structures during three earthquakes, it can be concluded that the deformation of the structures in silty sand is more than in silt. It is related to the mechanical and hydraulic characteristics of the subsoil.

The above discussion indicates the importance of soil type which may underestimate or overestimate the liquefaction-induced deformation of structure on liquefiable deposits depending on $N_{1(60)}, E$, fines content (FC) and permeability, respectively. 

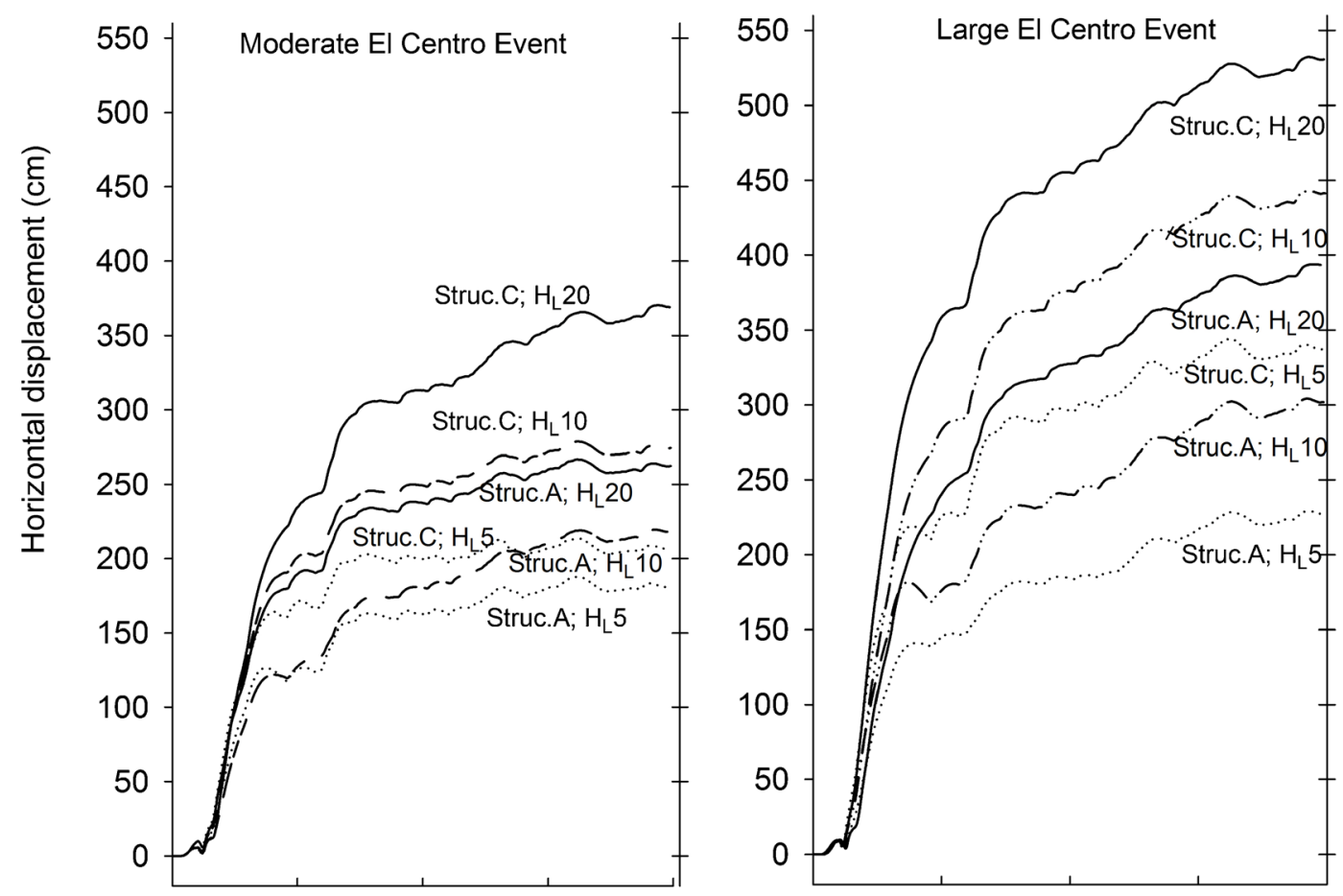

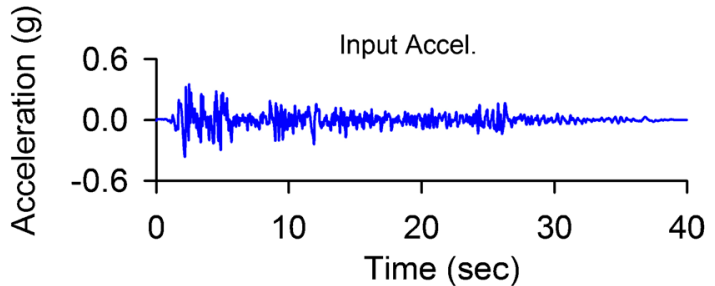

(a)

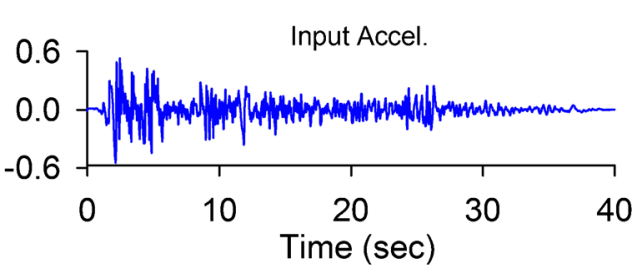

(b)

Figure 8. Horizontal displacement-time histories along the edge of the foundation in silty sand during: (a) the moderate $(\mathrm{PGA}=0.35 \mathrm{~g})$ and $(\mathbf{b})$ the large $(\mathrm{PGA}=0.55 \mathrm{~g})$ El Centro events.

\subsection{Effect of liquefiable soil thickness on the vertical and lateral displacement}

Many previous studies have shown that earthquake induced displacement of foundations on loose soils are related to, among other factors, the liquefiable soil layer thickness under the foundation. This parameter is one of the well-known engineering parameters and several researchers have examined its effects (Yoshimi and Tokimatsu 1977; Sancio et al. 2002; Bray and Sancio 2006). Thickness of the loose silt and sandy silt stratum $\left(H_{L}\right)$ above the bedrock and underlying foundation considered in the present study range from 5 to $20 \mathrm{~m}$. The effects of the thickness of liquefiable soil on the vertical and lateral displacement for different weights of the structure and PGA are plotted in figures 7 and 8. For PGA $=0.55 \mathrm{~g}$, vertical displacement, $S$, decreases significantly from 237 to 139 to $64 \mathrm{~cm}$ (structure C) as the thickness of liquefiable soil goes from 20 to 10 to $5 \mathrm{~m}$; less significant but still reductions are observed for $\mathrm{PGA}=0.35 \mathrm{~g}$. Both thicknesses of liquefiable soil and PGA play significant roles in determining the value of vertical displacement (figure 7). It is interesting to mention that thickness of liquefiable soil does not influence $S$ significantly: for PGA $=0.15 \mathrm{~g}$ (not shown here). The trends are similar to those shown in figure 7 for lateral displacement (figure 8).

In all presented simulations, the effects of the liquefiable soil layer thickness on the vertical and lateral displacements are more pronounced in the higher PGA and/or increased structure weight. In other words, responses are amplified due to increase in the thickness of liquefiable soil. The measure of this amplitude is more significant in heavier structures and during strong motions.

Consistent with the findings of Dashti et al. (2009a) and Sancio et al. (2002) for the relatively thin layers of liquefiable soil under heavier/lighter structures subjected to medium to large intense earthquakes have a tendency to undergo significant deformation that can cause serious damage. 


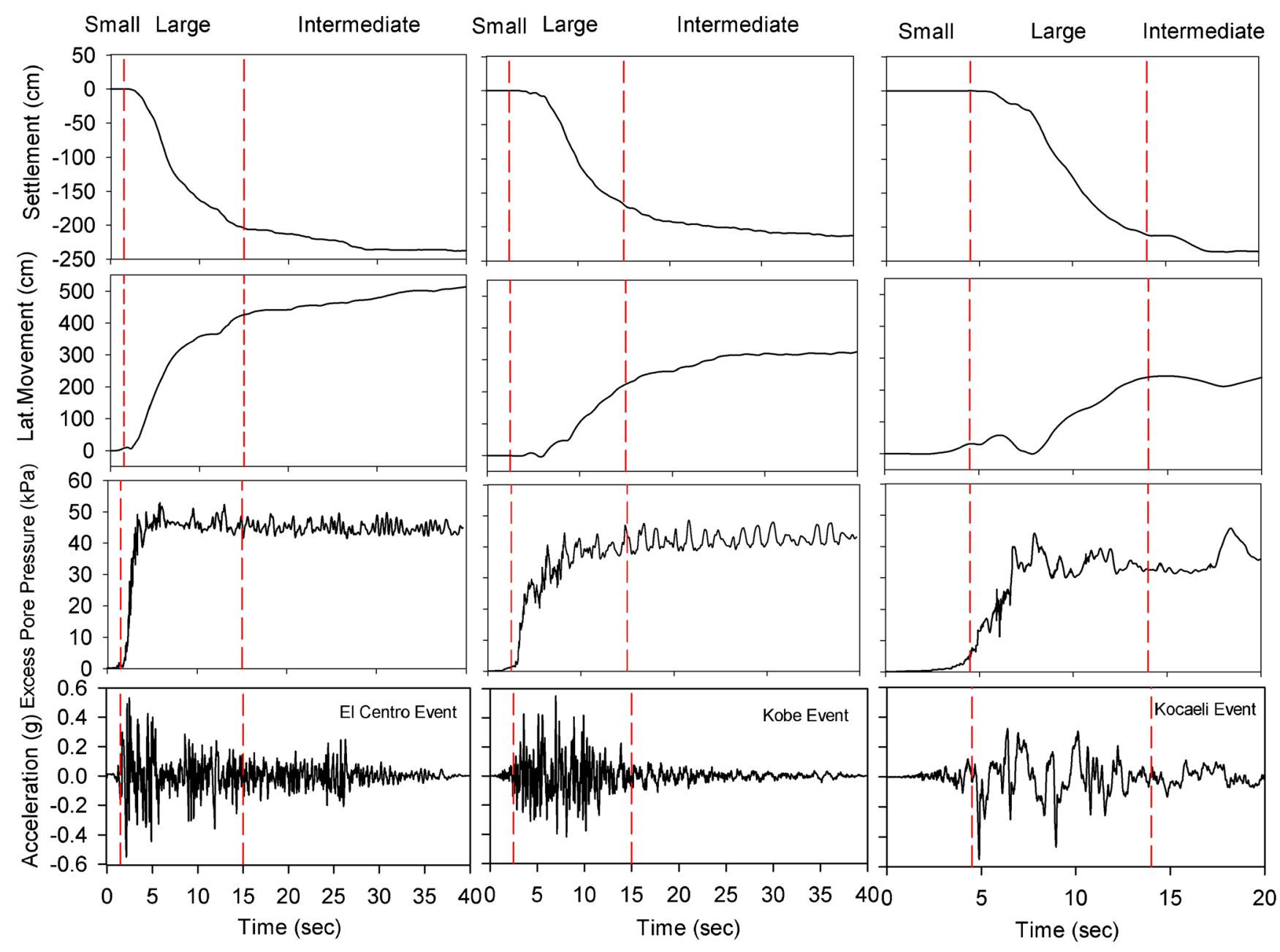

Figure 9. Acceleration, excess pore water pressure, lateral movement and settlement time histories for different events.

This indicates that even a relatively thin liquefiable layer can have dramatically different effects on the performance of the structure. Also further increment in the thickness of the liquefiable layers will lead to severe and more serious damage.

These results also emphasize the need for an improved understanding of the most important factors influencing liquefaction-induced deformation and thickness of liquefiable soil such as characteristics of earthquake motion. Hence, the effect of this key parameter is studied and discussed in the following section.

\subsection{The effects of the characteristics of the earthquake motion on seismic responses}

The objective is to study the effects of (a) the moment magnitude of earthquake $\left(M_{w}\right)$, (b) peak ground acceleration PGA, (c) PGV/PGA ratio, (d) the predominant period $\left(T_{p}\right)$, (e) the Arias intensity $\left(I_{\text {Arias }}\right)$, and (f) significant duration of motion $\left(D_{5-95}\right)$ during earthquake excitations on the seismic responses under shallow foundation for usual application and provide qualitative insight on the phenomenon. For the structure C, lateral displacement and excess pore water pressure in the El Centro event were slightly higher than the Kocaeli event. Whereas $M_{w \text { (Kocaeli) }}>M_{w \text { (El Centro) }}$ and specific energy density in the Kocaeli is much more than in the El Centro. It can be concluded that the moment magnitude of earthquake $\left(M_{w}\right)$ and specific energy density cannot be defined as parameters for the evaluation of seismic response by themselves.

Orense (2005) proposed an alternative approach, an evaluation procedure based on peak ground motion parameters (i.e., PGA and PGV). It was shown that incorporating both PGA and PGV can serve as thresholds in assessing the possible occurrence of liquefaction (Orense 2005). The results of the present study as given in tables 3 and 4 indicate that the $\mathrm{PGV} / \mathrm{PGA}$ ratio cannot adequately represent an accurate assessment of seismic responses or discriminator between liquefaction and non-liquefaction conditions. The reason is that although PGV/PGA ratio for the Kocaeli event is approximately twice its value for the 
Table 5. Summary of parametric trends calculated in numerical simulations.

\begin{tabular}{|c|c|c|c|}
\hline \multirow[b]{2}{*}{ Increase in parameter } & \multicolumn{3}{|c|}{ Seismic responses mechanisms in silty sand and silt soils under structure } \\
\hline & $\begin{array}{c}\text { Excess pore pressure } \\
(\mathrm{EPP})\end{array}$ & $\begin{array}{c}\text { Settlement } \\
(\mathrm{S})\end{array}$ & $\begin{array}{l}\text { Lateral displacement } \\
\qquad\left(D_{\boldsymbol{H}}\right)\end{array}$ \\
\hline Structure weight & $\uparrow$ & $\uparrow \uparrow$ & $\uparrow \uparrow$ \\
\hline Moment magnitude of earthquake, $M_{w}$ & $\uparrow$ & $\uparrow$ & $\uparrow$ \\
\hline Predominant period, $T_{p}(\mathrm{sec})$ & $\uparrow$ & $\uparrow$ & $\uparrow$ \\
\hline Peak ground acceleration, PGA & $\uparrow$ & $\uparrow \uparrow$ & $\uparrow \uparrow$ \\
\hline Arias intensity, $I_{\text {Arias }}$ & $\uparrow$ & $\uparrow$ & $\uparrow \uparrow$ \\
\hline The duration of strong motion $\left(D_{5-95}\right)$ & $\uparrow$ & $\uparrow$ & $\uparrow$ \\
\hline PGV/ PGA ratio & $\uparrow$ & $\uparrow$ & $\uparrow$ \\
\hline Depth, $d$ & $\uparrow$ & $\downarrow$ & $\downarrow$ \\
\hline Fine content (FC) & $\downarrow$ & $\downarrow$ & $\downarrow$ \\
\hline
\end{tabular}

a The direction of the arrows indicate the impact on the magnitude of the response value for an increase in the parameter, and the number of arrows indicates the relative importance of that parameter. Double-sided arrows indicate that both directions are possible depending on the specific conditions. Variation rate in different parameters under structure.

Kobe and El Centro events (PGA=0.55 g), but in comparison, excess pore water pressure and lateral displacements for both events, were more than that for the Kocaeli event. However, settlements for the Kocaeli event were more than for the other two events. Figures 5, 6 and 9 indicate the significant importance of other parameters such as frequency content, Arias intensity and the duration of strong motion, particularly for the examination of large deformation mechanism.

It can be seen that although each of the events in figure 9 have the same level of PGA, there was significantly more pore water pressure and lateral displacement response for the El Centro and Kobe records than for the Kocaeli earthquake record. This can be explained in terms of the frequency content in the time history records. Investigation of the predominant periods in soft soil, the most important topic in the seismic responses, have been examined and compared with seismic events recorded. Because higher level of excess pore water pressure and deformation may occur when the fundamental soil period are close to the earthquake predominant period leading towards resonance.

According to figure 2, during the Kocaeli event, higher amplitude Fourier occurred in the low frequencies range compared to two other events. On the other hand, predominant period of Kocaeli event is greater than others. It can cause more settlements than the Kobe and El Centro events. Even for $\mathrm{PGA}=0.55 \mathrm{~g}$, it makes more settlements than the Kobe which is approximately similar to the El Centro event, despite of having less Arias intensity and strong duration of motion. An important aspect to include in comprehensive characterization of ground motion is the duration of the strong earthquake. As shown in figure 9, most changes of pore water pressure and deformations would occur during the strong motion. Increase in the duration of strong motion leads to increase in the superstructure effect, because structure induced shear stress, which can be imposed to the soil elements for longer duration when their strength and stiffness has been dramatically decreased (figure 9). Therefore, it plays an important role in the damage of structure. It is noteworthy to mention that long-strong duration of the Kobe event was 1.2 times larger than those for the large Kocaeli event but structures settled less during the Kobe earthquake. From the observed trends for the Kocaeli event, it can be deduced that the event is strong enough to cause the major changes in the properties of soil in comparison with the Kobe event and settlement is surpassed. Also it shows that this parameter cannot give us complete information about the event feature by itself. Comparing figures 5 and 6 , it appears that the Arias intensity provides a somewhat better prediction for the value of response. Generally increase of Arias intensity in an event leads to an amplified response, especially in the case of lateral displacements. The lateral displacement increases with the Arias intensity of the earthquake increment. The various rates and amounts of understructure lateral displacements are similar to rates and amounts of $I_{\text {Arias }}$. The Arias intensity of an earthquake motion depends on the intensity, frequency content and duration of the motion (Dashti et al. 2009b). However, this clearly demonstrates the inability of $I_{\text {Arias }}$ to make true information about the settlements, during strong ground motion. As shown in figure 5, although the Arias intensity and significant duration of the large Kobe event were respectively, 1.4 and 1.2 times larger than those during the Kocaeli event, structures showed less settlement during the Kobe earthquake. 
Additional efforts are required for better understanding of other similarities and differences between each of characterized ground motion measures and there is a need to introduce new parameters such as the shaking intensity rate (Dashti et al. 2009b) for prediction of seismic liquefaction potential.

\section{Summary and conclusions}

The results of parametric seismic analyses of shallow foundation on deposits of loose sands containing fines or silts have been investigated. The results of numerical simulation illustrated the complex interactions between the key parameters (e.g., structure weight, soil type, liquefiable soil layer thickness and ground motion) and allowed the relative influence of some key parameters to be assessed. Table 5 summarizes the parametric trends observed in the numerical simulations of seismic responses during three earthquakes.

Several features of the dynamic response to various acceleration time histories are summarized below:

- Loose silty sand and silt deposits underwent notable non-uniform vertical deformation and deform horizontally underneath the structure foundation during each three ground motion events, especially during the strong shaking, despite its low $r_{u}$.

- Investigations show that, in addition to the excess pore water pressure ratio, deformations play an important role in prediction of seismic liquefaction potential. This suggests that the seismic remedial designs shall be based on displacement criteria rather than the factor of safety against liquefaction.

- The combined effects of vertical and horizontal deformations under structure compel structures to experience excessive tilt, which may even lead to severe damage to adjacent structures.

- As presented in table 1 , silt has the mechanical properties, e.g., $N_{1(60)}$ and $E$ less than silty sand. Simulation results in tables 3 and 4 have shown that in silty sand more deformations under the structure occur. This is because of the higher permeability coefficient (hydraulic characteristic) and lower cohesion of silty sand as compared to that of silt.

- Beneficial effects of the plastic fines (highplasticity soil deposits) significantly decrease with earthquake intensity and/or increase in structure weight.

- Responses are amplified due to increasing the thickness of liquefiable soil. The measure of this amplitude is more significant in heavier structures and during strong motions.

- The peak ground acceleration (PGA), the (PGV/PGA) ratio and the duration of strong motion $\left(D_{(5-95)}\right)$ cannot provide an accurate assessment of seismic responses or discriminator between liquefaction and non-liquefaction conditions.

- The lateral displacement increases as the Arias intensity of the earthquake increases. However, this clearly demonstrates the inability of $I_{\text {Arias }}$ to make true information about the settlements, during strong ground motion.

\section{References}

Adalier K, Elgamal A W and Martin G R 1998 Foundation liquefaction counter measures for earth embankments; J. Geotech. Geoenviron. Eng. ASCE 124 500-517.

Amini F and Qi G 2000 Liquefaction testing of stratified silty sands; J. Geotech. Geoenviron. Eng. ASCE 126 208-217.

Asgari A, Oliaei M and Bagheri M 2013 Numerical simulation of improvement of a liquefiable soil layer using stone column and pile-pinning techniques; J. Soil Dyn. Earthq. Eng. 51C 77-96.

Baziar M H and Dobry R 1995 Residual strength and largedeformation potential of loose silty sands; J. Geotech. Eng. ASCE 121 896-906.

Bouckovalas G D, Andrianopoulos K I and Papadimitriou A G 2003 A critical state interpretation for the cyclic liquefaction resistance of silty sands; J. Soil Dyn. Earthq. Eng. 23 115-125.

Boulanger R W 2003 High overburden stress effects in liquefaction analyses; J. Geotech. Geoenviron. Eng. 129 1071-1082.

Boulanger R W and Idriss I 2006 Liquefaction susceptibility criteria for silts and clays; J. Geotech. Geoenviron. Eng. ASCE 132 1413-1426.

Bray J D and Sancio R B 2006 Assessment of the liquefaction susceptibility of fine-grained soils; J. Geotech. Geoenviron. Eng. ASCE 132 1165-1177.

Bray J D, Sancio R B, Durgunoglu T, Onalp A, Youd T L, Stewart J P, Seed R B, Cetin O K, Bol E and Baturay M B 2004 Subsurface characterization at ground failure sites in Adapazari, Turkey; J. Geotech. Geoenviron. Eng. $A S C E \mathbf{1 3 0} 673-685$.

Byrne P M 1991 A cyclic shear-volume coupling and pore pressure model for sand; In: Second Int. Conf. Recent Advances in Geotechnical Earthquake Engg. and Soil Dynamics, St. Louis, Missouri, 2 47-55.

Byrne P M, Park S S, Beaty M, Sharp M, Gonzalez L and Abdoun T 2004 Numerical modeling of liquefaction and comparison with centrifuge tests; Can. Geotech. J. 41 $193-211$.

Carraro J, Bandini P and Salgado R 2003 Liquefaction resistance of clean and nonplastic silty sands based on cone penetration resistance; J. Geotech. Geoenviron. Eng. ASCE 129 965-976.

Dashti S, Bray J D, Pestana J M, Riemer M and Wilson D 2009a Centrifuge testing to evaluate and mitigate liquefaction-induced building settlement mechanisms; J. Geotech. Geoenviron. Eng. ASCE 13 918-929.

Dashti S, Bray J D, Pestana J M, Riemer M and Wilson D 2009b Mechanisms of seismically induced settlement of 
buildings with shallow foundations on liquefiable soil; J. Geotech. Geoenviron. Eng. ASCE 136 151-164.

Di Y and Sato T 2004 A practical numerical method for large strain liquefaction analysis of saturated soils; J. Soil Dyn. Earthq. Eng. 24 251-260.

Erten D and Maher M 1995 Liquefaction potential of silty soils; J. Soil Dyn. Earthq. Eng. 14 115-123.

Finn W 2000 State-of-the-art of geotechnical earthquake engineering practice; J. Soil Dyn. Earthq. Eng. 20 $1-15$.

Høeg K, Dyvik R and Sandbækken G 2000 Strength of undisturbed versus reconstituted silt and silty sand specimens; J. Geotech. Geoenviron. Eng. ASCE 126 606-617.

Hazirbaba K and Rathje E M 2009 Pore pressure generation of silty sands due to induced cyclic shear strains; $J$. Geotech. Geoenviron. Eng. ASCE 135 1892-1905.

Huang Y T, Huang A B, Kuo Y C and Tsai M D 2004 A laboratory study on the undrained strength of a silty sand from central western Taiwan; J. Soil Dyn. Earthq. Eng. 24 733-743.

Itasca F 2002 Fast Lagrangian Analysis of Continua, Version 4.0 User's Guide, Itasca Consulting Group, Inc., Thrasher Square East, 708p.

Kramer S L 1996 Geotechnical earthquake engineering; Prentice-Hall Civil Engineering and Engineering Mechanics Series, Upper Saddle River, NJ: Prentice Hall, 1996, 1.

Kuhlemeyer R L and Lysmer J 1973 Finite element method accuracy for wave propagation problems; J. Soil Mech. Found. ASCE Div, 99p.

Liu L and Dobry R 1997 Seismic response of shallow foundation on liquefiable sand; J. Geotech. Geoenviron. Eng. ASCE 123 557-567.

Lysmer J and Kuhlmeyer R 1969 Finite dynamic model for infinite media; J. Geotech. Geoenviron. Eng. ASCE 95 59-77.

Martin G R, Finn W D L and Seed H B 1975 Fundementals of liquefaction under cyclic loading; J. Geotech. Geoenviron. Eng. ASCE 101(GT5) 423-438.

Mittal R K, Gupta M K and Singh S 2004 Liquefaction behaviour of sand during vibrations; In: Proceedings of the 13th World Conference on Earthquake Engineering, Vancouver, B.C., Canada.

Orense R P 2005 Assessment of liquefaction potential based on peak ground motion parameters; J. Soil Dyn. Earthq. Eng. 25 225-240.

Pillai V and Byrne P 1994 Effect of overburden pressure on liquefaction resistance of sand; Can. Geotech. J. 31 53-60.

Polito C P, Green R A and Lee J 2008 Pore pressure generation models for sands and silty soils subjected to cyclic loading; J. Geotech. Geoenviron. Eng. ASCE $\mathbf{1 3 4}$ 1490-1500.
Polito C P and Martin II J R 2001 Effects of nonplastic fines on the liquefaction resistance of sands; J. Geotech. Geoenviron. Eng. ASCE 127 408-415.

Rayhani M and El Naggar M H 2008 Numerical modeling of seismic response of rigid foundation on soft soil; Int. J. Geomech. 8 336-346.

Rollins K M and Seed H B 1990 Influence of buildings on potential liquefaction damage; J. Geotech. Geoenviron. Eng. ASCE 116 165-185.

Salgado R, Bandini P and Karim A 2000 Shear strength and stiffness of silty sand; J. Geotech. Geoenviron. Eng. $A S C E \mathbf{1 2 6}$ 451-462.

Sancio R, Bray J, Stewart J, Youd T, Durgunoğlu H, Önalp A, Seed R, Christensen C, Baturay $M$ and Karadayllar T 2002 Correlation between ground failure and soil conditions in Adapazari, Turkey; J. Soil Dyn. Earthq. Eng. 22 1093-1102.

Shahir H and Pak A 2010 Estimating liquefaction-induced settlement of shallow foundations by numerical approach; Com. Geotech. 37 267-279.

Thevanayagam S and Martin G 2002 Liquefaction in silty soils-screening and remediation issues; J. Soil Dyn. Earthq. Eng. 22 1035-1042.

Vucetic M and Dobry R 1991 Effect of soil plasticity on cyclic response; J. Geotech. Geoenviron. Eng. ASCE 117 89-107.

Wang Z L, Makdisi F I and Egan J 2006 Practical applications of a nonlinear approach to analysis of earthquakeinduced liquefaction and deformation of earth structures; J. Soil Dyn. Earthq. Eng. 26 231-252.

White W, Lee I K and Valliappan S 1977 Unified boundary for finite dynamic models; J. Eng. Mech. Division 103 949-964.

Wijewickreme D, Sanin M V and Greenaway G R 2005 Cyclic shear response of fine-grained mine tailings; Can. Geotech. J. 42 1408-1421.

Yamamuro J A and Covert K M 2001 Monotonic and cyclic liquefaction of very loose sands with high silt content; J. Geotech. Geoenviron. Eng. ASCE 127 314-324.

Yang Z, Elgamal A, Adalier K and Sharp M K 2004 Earth dam on liquefiable foundation and remediation: Numerical simulation of centrifuge experiments; J. Eng. Mech $1301168-1176$.

Yasuda S, Wakamatsu K and Nagase H 1994 Liquefaction of artificially filled silty sands; ASCE 91-104.

Yoshida N, Tokimatsu K, Yasuda S, Kokusho $\mathrm{T}$ and Okimura T 2001 Geotechnical aspects of damage in Adapazari City during 1999, Kocaeli, Turkey earthquake; Soils and Foundations 41 25-45.

Yoshimi Y and Tokimatsu K 1977 Settlement of buildings on saturated sand during earthquakes; Soils and Foundations 17(1) 23-38.

Youd T L 200370 liquefaction mechanisms and induced ground failure; Interl. Geoph. 81 1159-1173. 